\title{
BMJ Open Cognitive complexity of clients and counsellors during motivation-based treatment for smoking cessation: an observational study on occasional smokers in a US college sample
}

Lucian Gideon Conway, ${ }^{1}$ Kari Jo Harris, ${ }^{2}$ Delwyn Catley, ${ }^{3}$ Laura Janelle Gornick, ${ }^{4}$ Kathrene Renee Conway, ${ }^{2}$ Meredith A Repke, ${ }^{1}$ Shannon C Houck ${ }^{5}$

To cite: Conway LG, Harris KJ, Catley D, et al. Cognitive complexity of clients and counsellors during motivationbased treatment for smoking cessation: an observational study on occasional smokers in a US college sample. BMJ Open 2017;7:e015849. doi:10.1136/ bmjopen-2017-015849

\section{- Prepublication history for} this paper is available online. To view these files, please visit the journal online (http://dx.doi. org/10.1136/bmjopen-2017015849).

Received 27 January 2017 Revised 1 September 2017 Accepted 11 September 2017

CrossMark

For numbered affiliations see end of article.

Correspondence to Dr Lucian Gideon Conway; luke.conway@umontana.edu

\section{ABSTRACT}

Objective Motivational interviewing (MI) is a widely used and promising treatment approach for aiding in smoking cessation. The present observational study adds to other recent research on why and when $\mathrm{Ml}$ works by investigating a new potential mechanism: integrative complexity.

Setting The study took place in college fraternity and sorority chapters at one large midwestern university. Participants Researchers transcribed MI counselling sessions from a previous randomised controlled trial focused on tobacco cessation among college students and subsequently scored clients' and counsellors' discussions across four counselling sessions for integrative complexity.

Interventions This is an observational secondary analysis of a randomised controlled trial that tested the effectiveness of MI. We analysed the relationship between integrative complexity and success at quitting smoking in the trial.

Primary and secondary outcome measures Success in quitting smoking:Participants were categorised into two outcome groups (successful quitters vs failed attempters), created based on dichotomous outcomes on two standard variables: (1) self-reported attempts to quit and (2) number of days smoked via timeline follow-back assessment procedures that use key events in participants' lives to prompt their recall of smoking.

Results We found (1) significantly higher complexity overall for participants who tried to quit but failed compared with successful quitters (standardised $\beta=0.36, p<0.001$, (Lower Confidence Interval.) $L C l=0.16$, (Upper Confidence Interval) $U C l=0.47)$ and (2) the predictive effect of complexity on outcome remains when controlling for standard motivational and demographic variables (partial $r(102)=-0.23, p=0.022)$.

Conclusions Taken together, these results suggest that cognitive complexity is uniquely associated with successful quitting in Ml controlled trials, and thus may be an important variable to more fully explore during treatment.

\section{Strengths and limitations of this study}

- Our study proposes and tests part of a new psychological model for application to motivational interviewing (MI) interventions. We evaluate the tenability of using cognitive complexity to predict outcomes during MI treatment.

- This study provides a unique research contribution by directly evaluating the relationship between cognitive complexity and success during $\mathrm{Ml}$ treatment sessions. It does so in an ecologically valid fashion by scoring complexity during actual MI sessions.

- Our sample included a college population of occasional smokers. While this population is very important in its own right, it is not necessarily representative of other groups of smokers and therefore should not be generalised beyond this population.

- Due to the observational design of the study, we cannot make a strong claim about causality. Rather, we argue that these data are largely consistent with the model we propose, and future studies would be necessary to rule out alternative possibilities.

\section{INTRODUCTION}

Tobacco use continues to be the leading cause of preventable death and disease in the USA and many parts of the world..$^{1-3}$ One of the most widely used and recommended behavioural change approaches to helping persons quit smoking is motivational interviewing (MI) ${ }^{4-7} \mathrm{MI}$ is designed to help clients with the problem of ambivalence about change, such that it enhances motivation for behaviour change through a collaborative, goal-oriented style of communication. ${ }^{8}$ MI has been demonstrated to heighten smokers' readiness to quit, ${ }^{9}$ increase the likelihood of attempts to quit smoking ${ }^{10-12}$ and sometimes lead to greater cessation. ${ }^{7} 10$ 13-19 
Meta-analyses show modest positive effects for MI on smoking outcomes. ${ }^{5} 2021$

\section{Background/rationale}

While MI sometimes yields desired change outcomes, it is not yet fully understood how exactly MI evokes change. Numerous theories have been proposed as potential mechanisms of action for MI, including self-determination theory, ${ }^{22}$ cognitive dissonance theory, ${ }^{23}$ self-perception theory, ${ }^{23}$ behaviour analytic principles ${ }^{24}$ and a combination of the elicitation of change talk and relationship factors. ${ }^{25}$ Despite the widespread use of MI for smoking cessation, a full understanding of the mechanisms by which MI might promote cessation is still emerging, and studies have sometimes failed to find clear explanations of its success. ${ }^{26}$ To improve the effectiveness of MI, it is important to better establish the underlying pathways by which MI influences smoking behaviour. ${ }^{7}$ This is especially the case for the use of MI for smoking cessation, where the modest treatment effects and variability of findings across studies suggest the treatment can be improved. ${ }^{20}{ }^{21}$ The purpose of our research is to help fill in this gap by exploring one variable that may be associated with MI's effectiveness and yet is novel in its application to MI research: cognitive complexity.

\section{Cognitive complexity}

Cognitive complexity has been conceptualised in many different ways, but it is broadly defined as recognising multiple dimensions of a particular topic or issue. ${ }^{27-29} \mathrm{~A}$ cognitively simple approach focuses on only one idea or dimension (eg, 'smoking is bad'), whereas a more cognitively complex approach refers to the acknowledgement of more than one idea or dimension (eg, 'smoking has bad health consequences, but it also has good social consequences'). The construct of complexity has been used to understand such diverse phenomena as success in treating personality disorders, ${ }^{30}$ the genetic heritability of attitudes, ${ }^{31}$ the psychology of ageing and death, ${ }^{32}$ Holocaust survivors' coping mechanisms, ${ }^{33}$ successful parenting ${ }^{34}$ and psychological extremism. ${ }^{2855-37}$ Although cognitive complexity has been characterised as both a personality trait ${ }^{38-40}$ and as a state that fluctuates via environmental circumstances and motivations, ${ }^{28} 3141-45$ it is clearly changeable over time, ${ }^{28} 31323641-44$ even with brief interventions. ${ }^{46} 47$

Below, we discuss in more depth why, although the application of cognitive complexity to MI is novel, there are reasons to believe it may help us understand why MI works-and ultimately help make it more effective. First, however, we explain in more detail the nature of the measurement of cognitive complexity itself.

\section{Open-ended complexity measurements}

Cognitive complexity has been measured in many different ways. One way is to use self-report questionnaires. ${ }^{38-40} \mathrm{~A}$ different method involves scoring open-ended statements for the complexity of their structure. ${ }^{28} 313241-43$ These open-ended methods involve the evaluation and subsequent scoring of the multidimensionality of the actual thoughts of people as they represent themselves without asking the persons any specific complexity-relevant questions. As such, open-ended methods allow researchers to obtain direct measurements of the complexity of participants' actual thoughts in an unobtrusive way. Because we are interested in directly capturing the real-time thoughts of participants in smoking interventions in as genuine a manner as possible, this open-ended approach was used for the present research. In particular, we chose the most commonly used and most widely validated openended measurement: integrative complexity. ${ }^{41}$ Integrative complexity involves assigning open-ended materials scores based on the levels of (a) differentiation, which refers to one's ability to distinguish between different dimensions of an issue and (b) integration, or the degree to which differentiated dimensions are connected into a larger framework. Complexity scores are assigned based solely on the structure of a passage rather than its meaning or content, ${ }^{41}$ and as a result, integrative complexity can capture a wide range of phenomena.

Cognitive complexity and smoking cessation in MI counselling

Cognitive complexity has been tied to health-related outcomes $^{32}{ }^{33} 48-50$ but has never been directly tied to MI or smoking outcomes in particular. However, there is much conceptual overlap between MI, smoking outcomes and complexity. Below, we discuss a model of MI's overlap with complexity.

\section{A basic model of complexity and Ml counselling success}

The current research is designed to test one part of a larger model focusing on different psychological phases clients may go through during MI treatment. This model is drawn from work and theory on cognitive complexity, ${ }^{28} 3151$ MI, ${ }^{81152}$ ambivalence ${ }^{53-55}$ and phase modelling. ${ }^{56}$ It is also complementary to other motivational models suggesting the importance of resisting impulses to smoke when they occur. $^{57}$

A simplified version of the model is presented in figure 1. In the present study, we focus only on the connection from occasional/exploratory smokers to end of

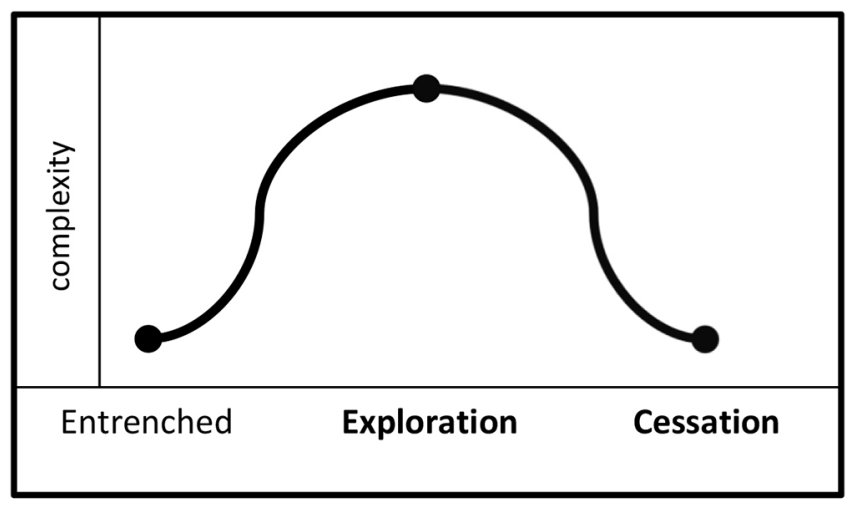

Figure 1 Proposed model of cognitive complexity during successful smoking cessation. 
treatment (middle-to-right part of figure 1). This model suggests that occasional or exploratory smokers may have too much complexity and that cognitive simplicity is more likely to be associated with lasting positive behaviour change. This follows from the psychology of simple versus complex thinking: the advantages of simplicity revolve around consistency, ${ }^{58}$ maintained action and resolve ${ }^{43} 59$ and strength of beliefs. ${ }^{28}{ }^{59-63}$ These advantages weigh heavily in favour of simplicity for producing positive, lasting, smoking-related change.

\section{Objectives}

This study was a secondary analysis of a randomised clinical trial of MI for smoking cessation in college students. ${ }^{11}$ In line with our goal to explore the benefits of simplicity as expected by our model, we focused on occasional smokers. We divided people into outcome groups (those who attempted to quit but failed and those who attempted to quit and succeeded) and scored a subsample of participants' sessions for both client and counsellor complexity. Three hypotheses were tested: (1) successful quitters will show lower overall complexity than those who attempted to quit but failed. (2) Cognitive complexity will show discriminant validity above and beyond more traditional motivational and descriptive variables. (3) Successful quitters will show a greater drop in complexity from beginning to end of treatment compared with those who attempted to quit who failed.

Because counsellor simplicity in other contexts is related to client success, ${ }^{30}$ it is possible that (as expected for clients) counsellors in sessions with clients who ultimately quit will show lower levels of complexity compared with sessions with failed attempters. Thus, we further tested the degree that counsellor complexity was associated with client success, although we made no firm hypotheses.

\section{METHODS}

\section{Ethics statement}

Participants provided their written informed consent and received course credit for participation. Study procedures were reviewed and monitored by institutional review boards at the University of Montana and University of Missouri.

\section{Study design}

We follow Strengthening the Reporting of Observational Studies in Epidemiology reporting guidelines. This is an observational secondary analysis of a group randomised clinical trial that compares the complexity of those who succeeded in quitting smoking during the trial with those who did not. We also included possible moderators (client vs counsellor, session number) and multiple covariates. Our procedures closely followed other research that has used linguistic analyses in MI contexts to analyse success or failure. ${ }^{62}$ Specifically, like prior research, we (1) focused on participants who had been assigned to an MI condition in a prior study ${ }^{52}$, (2) used explicit criteria to divide participants up into categories relevant to ultimate outcome prior to scoring ${ }^{652}$ (3) used linguistic scoring systems to score clients during MI sessions by trained scorers blind to outcome group ${ }^{62}$ and (4) compared outcome groups by their scores on these linguistic measures. ${ }^{652}$ Thus, while we are using an entirely novel linguistic scoring system, we followed procedures parallel to similar MI work.

\section{Setting}

More information about the RCT on which our secondary analysis was conducted ${ }^{11}$ and recruitment procedures ${ }^{48}$ can be found elsewhere. In brief, students enrolled in college fraternity and sorority chapters were recruited to participate in a health study. Chapter members were eligible if they reported smoking one or more cigarettes in the prior 30 days, regardless of their interest in quitting. Members were randomised by chapter to receive either four individual sessions of MI for smoking cessation or for increasing consumption of fruits and vegetables. Because our focus is on understanding success and failure in MI conditions, only those assigned to the MI for smoking condition $(n=245)$ were considered for the present study.

\section{Participants}

Consistent with the idea that they can be characterised as being occasional/exploratory smokers at the beginning of treatment, these 245 participants $(35.5 \%$ female, $4.1 \%$ non-white and $11.1 \%$ smoked every day) were generally moderate in motivation to quit smoking (mean $=5.4$, on $0-10$ scale, where 10 is very motivated), whereas they were high in confidence that they had the ability to quit if they wanted to (mean 8.9, 0-10 scale, where 10 is very confident). MI sessions (typically $20-30 \mathrm{~min}$ long) were run by rigorously trained clinical and counselling graduate students, and fidelity of sessions was monitored throughout the study. Sessions were subsequently transcribed. The University of Montana and The University of Missouri Institutional Review Boards approved and monitored the study procedures.

\section{Outcome variable}

Our purpose was to compare the complexity levels of sessions that were ultimately successful (where clients ultimately quit smoking) with those that were not successful (where clients did not ultimately quit smoking). Thus, for our secondary analysis, we did not use all of the participants in the original study. It is this secondary selection process (and not the process of recruitment and selection from the original randomised trial) that we describe here.

In order to maximise power, selection of participants for inclusion was quasirandom. Participants were first categorised into two outcome groups created based on dichotomous outcomes on two variables. The first, self-reported attempts to quit, was assessed by responses to the question 'Since the study started, have you made a serious 
and concerted effort to quit smoking?' (yes $/$ no $^{64}$;). The second, smoking status, was assessed by self-reported number of days smoked using the highly validated timeline follow-back assessment procedures that use key events in participants' lives to prompt their recall of smoking $(0$ days $/ 1-30$ days ${ }^{64}$;). Participants were categorised into two groups: (1) failed attempters (reported making one or more quit attempts and reported smoking on 1 or more days out of the past 30 days at the end of treatment) and (2) successful quitters (reported making one or more quit attempts and reported not smoking on any days out of the past 30 days at end of treatment). Participants who made no attempts to quit (based on self-reported attempts to quit) were dropped from the present secondary analysis.

After this categorisation process was complete, participants were randomly selected from within these outcome groups. This method ensured an essentially equal number of participants in each outcome group (successful quitters and failed attempters), which maximises power and increases interpretability of findings.$^{65}$ Because we want to compare successful quitters with failed attempters, this method maximises our likelihood of finding an interpretable effect and offered enough power $(n=1100$ paragraphs, detailed below) in each condition. Furthermore, this method ensured that the selection of final participants in each category was random, thus reducing the likelihood of any selection biases.

Originally, there were 55 participants in the failed attempter group, and 33 participants in the quitter group. From each group, we randomly selected 16 participants. One participant from the successful quitter group was later dropped after review of their session transcripts revealed they were actually in the non-smoking MI condition from the original randomised trial, resulting in a sample of 31 participants. All available MI sessions of each of the 31 participants in the final sample were then transcribed. (Due to the fact that some participants did not attend all the counselling sessions, six of the participants were missing one of the four transcripts, and four were missing two of the transcripts, resulting in 110 session transcripts. Scores were aggregated by computing the mean of available data.). Each session transcript was split to create two documents from the original; this was done to create separate documents containing client statements and counsellor statements. As a result, there were 220 documents used for analysis in the present study (110 client documents and 110 counsellor documents).

\section{Complexity variables}

In accord with norms in the complexity field, ${ }^{66} 67$ we selected five paragraphs per document (220 documents $\times$ five paragraphs each, $n=1100$ ). A paragraph was considered a single response that was not interrupted directly by a significant discussion or question from the other person. Because of the large variability in paragraphs in terms of length and context (eg, some were one-word answers and some were lengthy paragraphs), we followed a strategy similar to that used in past research ${ }^{61}$ by selecting the five longest responses for analysis (by word count) to prevent bias due to statement length.

Following the highly validated integrative complexity scoring system, ${ }^{66}$ each paragraph was presented to trained integrative complexity scorers in a random order. Coders were blind to the purpose of the project and to the outcome condition of the participant paragraphs they were scoring. As required by the integrative complexity system, ${ }^{66}$ coders assigned an integrative complexity score between 1 (simplistic thinking) and 7 (complex thinking). Scores are assigned based on the levels of (A) differentiation and (B) integration. Specifically, a score of 1 indicates simplistic thinking (no differentiation of dimensions), whereas a score of 3 indicates clear differentiation of at least two dimensions (but no integration). A score of 5 contains both differentiation of at least two dimensions and subsequent integration of those differentiated dimensions. Finally, a score of 7 reflects the highest level of complex thinking, marked by larger hierarchical thinking and/or an integration of separate integrated dimensions.

We also scored two subcomponents of integrative complexity, elaborative complexity and dialectical complexity. Elaborative complexity occurs when someone complexly defends a singular point of view (eg, 'smoking is bad for my overall health, and bad for my teeth'), while dialectical complexity occurs when someone recognises that competing points of view are both legitimate (eg, 'smoking is bad for my health, but good for my social life'; see refs 2831 36). Each subconstruct was scored on the same 1-7 scale. A passage was first scored for overall integrative complexity, then trained coders assessed how much of that score was due to elaborative complexity or dialectical complexity. ${ }^{28}$ Therefore, all passages received three scores: one for overall integrative complexity, and one for each subcomponent (elaborative and dialectical).

Each of the 1100 selected paragraphs were scored independently by five extensively trained integrative complexity coders who had previously achieved a reliability level for integrative complexity of at least 0.85 with an expert coder using established procedures ${ }^{66}$ and successfully coded the two subcomponents in prior research. ${ }^{2831}$ The paragraphs were presented to coders in a random order. Coders were blind to cessation outcome type and session number of the paragraphs they were coding and were further unaware of the larger theoretical approach of the project. In a manner similar to prior research, ${ }^{31}$ any individual coder's score that substantially deviated from the overall average coders' score (a difference of an individual coder from the group of coders $>2$ ) was removed and replaced with the mean paragraph score. The resulting summary scores showed satisfactory interrater agreement for all three variables (integrative complexity alpha $=0.86$, dialectical complexity alpha $=0.84$ and elaborative complexity alpha $=0.78$ ).

For all analyses below, we aggregate the five paragraphs from each document into an average score and use the document as the unit of analysis $(n=220)$. 


\section{Control variables}

To test the degree that cognitive complexity shows discriminant validity above and beyond established motivational variables, we controlled for a subset of relevant variables collected in the parent study: (1) motivation to quit smoking $^{11}$, (2) confidence in ability to quit smoking ${ }^{11}$, (3) self-regulation, ${ }^{68}$ (4) self-efficacy ${ }^{69}$ and (5) outcome expectations ${ }^{70}$ and self-evaluative emotions. ${ }^{71}$ All of these variables were collected at pretreatment (prior to session 1 ), and some were additionally collected at end of treatment (after session 4). We controlled in each case for the mean scores at pretreatment and (when available) end of treatment separately, as well as a difference score (when available) accounting for change on the variable over time.

To show the added effects of cognitive complexity beyond possible confounding factors, we further controlled for an additional set of smoking-relevant variables collected at pretreatment baseline: (1) nicotine dependence, ${ }^{72}$ (2) contemplation ladder for quitting smoking, ${ }^{73}$ (3) prior history of quit attempts ${ }^{74}$ and (4) cigarettes smoked per month at baseline. ${ }^{75}$

\section{Study size}

Study size was originally proposed as a function of power estimates made using $G^{*}$ Power. These power estimates used parameters from a similar pilot study with fewer participants in each outcome group (eight) and fewer sessions per participant (two). As can be seen in our results, the resulting study was adequately powered for our main conclusions.

\section{Statistical analyses and summary of variables in design}

All data analyses were performed using SPSS (V.22), and we used an alpha level of. 05 to determine statistical significance. We used two complementary statistical approaches. First, we used a series of factorial analyses of variance (ANOVAs). For this approach, our independent variables were outcome group (successful quitters vs failed attempters), session number (one, two, three or four) and person type (client vs counsellor). Our dependent variables in these ANOVAs were integrative complexity, dialectical complexity and elaborative complexity.

Conceptually, the use of outcome group as an (Independent Variable) IV and integrative complexity as a (Dependent Variable) DV is an arbitrary distinction used to capture a relationship between variables and should not be interpreted to imply causality in either direction. Indeed, integrative complexity in the sessions comes before the variables used to categorise into the dichotomous outcome groups (and thus, any causality would likely go in the opposite direction). We use an ANOVA with outcome groups as the IV because this is the clearest way to illustrate the potential interactive relationship between outcome, session, person type and complexity. However, the results would be the same if we used correlational analyses with integrative complexity predicting outcome (or vice versa).

Indeed, we additionally used a correlational approach to some analyses. In these correlational analyses, we test the larger effect of cognitive complexity on outcome while further controlling for our covariates: motivation to quit smoking, confidence in ability to quit smoking, self-regulation, self-efficacy, outcome expectations, self-evaluative emotions, nicotine dependence, contemplation ladder for quitting smoking, prior history of quit attempts and cigarettes smoked per month at baseline.

Regardless of statistical method, it is the relationship between the complexity of the sessions and the outcome that we are interested in illustrating, and we do not mean to imply direct causality either way. We return to this issue in the discussion.

\section{RESULTS}

\section{Primary analyses}

Table 1 shows the overall pattern of integrative complexity for both counsellors and clients. A 2 (person type: client or counsellor) $\times 2$ (outcome: successful quitter or failed attempter) $\times 4$ (session number: 1, 2, 3 or 4) ANOVA on integrative complexity yielded the predicted main effect of

\begin{tabular}{|c|c|c|c|c|c|}
\hline & & Failed attempter & Successful quitter & $\mathbf{F}$ & p Value \\
\hline \multirow[t]{5}{*}{ Client } & Session 1 & 2.11 & 1.88 & $\mathrm{n} / \mathrm{a}$ & $\mathrm{n} / \mathrm{a}$ \\
\hline & Session 2 & 1.84 & 1.53 & $\mathrm{n} / \mathrm{a}$ & $\mathrm{n} / \mathrm{a}$ \\
\hline & Session 3 & 1.85 & 1.48 & $\mathrm{n} / \mathrm{a}$ & $\mathrm{n} / \mathrm{a}$ \\
\hline & Session 4 & 1.96 & 1.57 & $\mathrm{n} / \mathrm{a}$ & $\mathrm{n} / \mathrm{a}$ \\
\hline & All sessions & 1.94 & 1.63 & 17.36 & $<0.001$ \\
\hline \multicolumn{6}{|c|}{ Counsellor } \\
\hline & Session 1 & 1.99 & 1.76 & $\mathrm{n} / \mathrm{a}$ & $\mathrm{n} / \mathrm{a}$ \\
\hline & Session 2 & 1.94 & 1.67 & $\mathrm{n} / \mathrm{a}$ & $\mathrm{n} / \mathrm{a}$ \\
\hline & Session 3 & 1.81 & 1.42 & $\mathrm{n} / \mathrm{a}$ & $\mathrm{n} / \mathrm{a}$ \\
\hline & Session 4 & 1.80 & 1.55 & $\mathrm{n} / \mathrm{a}$ & $\mathrm{n} / \mathrm{a}$ \\
\hline & All sessions & 1.89 & 1.60 & 14.68 & $<0.001$ \\
\hline
\end{tabular}


outcome on complexity: complexity was lower in sessions for successful quitters (Mean=1.91) than for failed attempters $\quad(M e a n=1.62), \quad F(1,203)=32.04$, two-tailed $\mathrm{p}<0.001$. Analyses also revealed a main effect for session, with complexity generally lower at the end of treatment than at the beginning (session 1: Mean=1.94; session 2: Mean=1.76; session 3: Mean=1.66; session 4: Mean=1.72), $F(1,203)=5.27$, two-tailed $\mathrm{p}=0.002$. No other significant effects emerged (counsellor/client main effect $F(1,203)=0.52$, two-tailed $\mathrm{p}=0.471$; counsellor $/$ client $\times$ outcome $F(3,203)=0.13$, two-tailed $\mathrm{p}=0.722$; counsellor / client $\times$ session $F(3,203)=1.05$, two-tailed $\mathrm{p}=0.372$; session $\times$ outcome $F(3,203)=0.33$, two-tailed $\mathrm{p}=0.806$; three-way interaction $F(3,203)=0.09$, two-tailed $\mathrm{p}=0.964)$.

Focused ANOVAs revealed a similar set of inferential statistics for counsellors and clients separately: the key test revealed the same main effects for outcome group on integrative complexity for both clients and counsellors (see table 1 for individual test information), with both clients and counsellors showing significantly reduced complexity during successful quitting sessions. All other effects for integrative complexity were also similar to those combining clients and counsellors.

\section{Covariation analyses}

Because primary significant results of interest involved the relationship between outcome and integrative complexity (IC), we focused correlational covariation analyses on this relationship. We first controlled for the average sentence length of the document; doing so did not alter the relationship between IC and outcome (dummy coded as failure $=0$, success $=1$ ) for the whole sample, client-only analyses or counselor-only analyses (all partial $r \mathrm{~s}<-0.33$, all two-tailed $\left.p^{\prime} s<0.001\right)$. This reveals that the key effect is not an artefact of longer or shorter conversational styles.

To remove unnecessary noise from the remaining covariation analyses, we first correlated all possible covariates from pretreatment and post-treatment with both client integrative complexity and outcome. We then only included covariates in the final analyses that were significant predictors of both IC and outcome.

No post-treatment measures were significantly correlated with both, but five pretreatment measures met these criteria for inclusion: confidence in quit ability, negative outcome expectations, self-efficacy (positive affect in social situations subscale), self-evaluation of emotions and self-regulation. For these five covariates, we ran sets of partial correlations with (1) all five as covariates entered at once and (2) each of them entered separately. These analyses revealed that integrative complexity remained a significant negative predictor of success in quitting smoking when all five covariates were entered as predictors simultaneously (IC-Success partial $r(102)=-0.23$, two-tailed $\mathrm{p}=0.022$ ) and for each predictor entered separately. The single predictor accounting for the most variance was self-efficacy for positive affect in social situations, but a significant effect of IC on success remained when accounting for that predictor (IC-Success partial $r(106)=-0.26$, two-tailed $\mathrm{p}=0.007$ ).

We further included covariates representing change scores from beginning to end of treatment for the two variables for which information was available (self-evaluation and self-regulation), and these change scores did not affect the IC-Success relationship (IC-Success partial $r$ $(105)=-0.35$, two-tailed $\mathrm{p}<0.001)$.

In summary, these analyses demonstrate the discriminant validity of integrative complexity in predicting client success in MI treatments: accounting for multiple motivational and smoking-related factors, a significant predictive ability of integrative complexity remains.

\section{Dialectical and elaborative complexity}

For all primary ANOVA analyses, we performed parallel sets of analyses for dialectical complexity and elaborative complexity. For the main effect of outcome, these analyses directly paralleled those for overall integrative complexity, with successful quitter sessions showing significantly lower dialectical and elaborative complexity

\begin{tabular}{|c|c|c|c|c|c|}
\hline & & Failed attempter & Successful quitter & $\mathbf{F}$ & p Value \\
\hline \multirow[t]{5}{*}{ Client } & Session 1 & 1.80 & 1.64 & $\mathrm{n} / \mathrm{a}$ & $n / a$ \\
\hline & Session 2 & 1.61 & 1.38 & $\mathrm{n} / \mathrm{a}$ & $\mathrm{n} / \mathrm{a}$ \\
\hline & Session 3 & 1.69 & 1.36 & $\mathrm{n} / \mathrm{a}$ & $\mathrm{n} / \mathrm{a}$ \\
\hline & Session 4 & 1.75 & 1.41 & $\mathrm{n} / \mathrm{a}$ & $\mathrm{n} / \mathrm{a}$ \\
\hline & All sessions & 1.71 & 1.45 & 18.93 & $<0.001$ \\
\hline \multicolumn{6}{|c|}{ Counsellor } \\
\hline & Session 1 & 1.75 & 1.53 & $\mathrm{n} / \mathrm{a}$ & $\mathrm{n} / \mathrm{a}$ \\
\hline & Session 2 & 1.59 & 1.51 & $\mathrm{n} / \mathrm{a}$ & $\mathrm{n} / \mathrm{a}$ \\
\hline & Session 3 & 1.54 & 1.25 & $\mathrm{n} / \mathrm{a}$ & $\mathrm{n} / \mathrm{a}$ \\
\hline & Session 4 & 1.53 & 1.41 & $\mathrm{n} / \mathrm{a}$ & $\mathrm{n} / \mathrm{a}$ \\
\hline & All sessions & 1.60 & 1.43 & 8.37 & 0.005 \\
\hline
\end{tabular}


Table 3 Elaborative complexity by success/failure group, session and client/counsellor

\begin{tabular}{|c|c|c|c|c|c|}
\hline & & Failed attempter & Successful quitter & $\mathbf{F}$ & p Value \\
\hline \multirow[t]{4}{*}{ Client } & Session 1 & 1.39 & 1.28 & $\mathrm{n} / \mathrm{a}$ & $\mathrm{n} / \mathrm{a}$ \\
\hline & Session 2 & 1.28 & 1.17 & $\mathrm{n} / \mathrm{a}$ & $\mathrm{n} / \mathrm{a}$ \\
\hline & Session 4 & 1.22 & 1.19 & $\mathrm{n} / \mathrm{a}$ & $\mathrm{n} / \mathrm{a}$ \\
\hline & All sessions & 1.26 & 1.19 & 4.12 & 0.045 \\
\hline & Session 1 & 1.35 & 1.24 & $\mathrm{n} / \mathrm{a}$ & $\mathrm{n} / \mathrm{a}$ \\
\hline & Session 2 & 1.39 & 1.21 & $\mathrm{n} / \mathrm{a}$ & $\mathrm{n} / \mathrm{a}$ \\
\hline & Session 3 & 1.32 & 1.17 & $\mathrm{n} / \mathrm{a}$ & $\mathrm{n} / \mathrm{a}$ \\
\hline & Session 4 & 1.35 & 1.14 & $\mathrm{n} / \mathrm{a}$ & $\mathrm{n} / \mathrm{a}$ \\
\hline & All sessions & 1.35 & 1.19 & 16.70 & $<0.001$ \\
\hline
\end{tabular}

However, as can be seen in tables 2 and 3, the descriptive pattern of dialectical and elaborative complexity across sessions differed for clients and counsellors. To better understand this pattern, we computed a variable representing the relative tendency of participants to use dialectical versus elaborative complexity (computed as dialectical complexity - elaborative complexity, as used in prior research ${ }^{31} 45$ ). We call this variable exploratory complexity.

compared with failed attempter sessions for both clients (see tables 2 and 3 ).

A 2 (person type: client or counsellor) $\times 2$ (outcome: successful quitter or failed attempter) $\times 4$ (session number: $1,2,3$ or 4) ANOVA on exploratory complexity yielded a main effect of outcome: exploratory complexity was significantly lower in sessions for successful quitters than for failed attempters, $F(1,203)=6.02$, two-tailed $\mathrm{p}=0.015$. However, this effect was significantly qualified by an outcome $\times$ person type interaction, while no difference between success and failure sessions emerged for counsellors (successful quitter: Mean=0.24; failed attempter: Mean $=0.25$ ), the difference between success and failure sessions was strong for clients (successful quitter: Mean $=0.26$; failed attempter: Mean $=0.44)$, interaction $F(1$, 203) $=4.45$, two-tailed $\mathrm{p}=0.036$.

\section{DISCUSSION}

In line with study objectives, the present results show the discriminant validity of cognitive complexity in predicting client success during an MI intervention. Clients who ultimately quit smoking showed lower integrative complexity than those who tried to quit but failed, and this effect remained even when controlling for a large array of variables. Those control variables included superficial markers such as sentence length, pre-existing tobacco use and a large number of motivational variables that have been shown to predict smoking cessation success in prior research. In short, these data support the conclusion that low integrative complexity is uniquely associated with success in quitting smoking for occasional smokers in MI contexts.

Although the present study is the first test of the effect of integrative complexity on smoking cessation in MI contexts, the idea that simplicity is associated with long-term successful health outcomes is consistent with research suggesting that more complex strategies/plans decrease behavioural adherence to both weight loss plans ${ }^{49}$ and health plans in the elderly. ${ }^{50}$ It is further consistent with research-using the same open-ended measurement of complexity as the present project-that reveals higher levels of cognitive complexity in both clients and counsellors predict poor outcomes in a treatment for personality disorders, ${ }^{76}$ as well as work demonstrating higher levels of complexity in descriptions of maladaptive (vs adaptive) coping episodes. ${ }^{77}$ In each of these cases, simplicity was associated with positive behavioural outcomes. Thus, this work fits in with prior work suggesting that, ultimately, cognitive simplicity may be required for sustaining healthy behaviours.

Potential implications for MI counselling and future directions Why might these results matter for MI counselling? In the present study, clients' levels of cognitive complexity during real-time sessions was associated with their ultimate success in quitting smoking in ways consistent with power of simplicity suggested by the right side of our model (see figure 1). Given that the mechanisms by which MI works, and correspondingly the reasons why it sometimes fails to work, are not well understood ${ }^{26}$; this initial evidence that cognitive complexity matters during treatment could be of vital importance.

For example, if (as our data suggest) a reduction in cognitive complexity is associated with success, it may be that the very motives and goals that MI is designed to increase might sometimes influence complexity in a direction exactly opposite of what is conducive to quitting smoking. Indeed, this fact might help explain the evidence that MI can be counterproductive for individuals who are already ready to change ${ }^{78}$ as well as variability in studies testing MI's success in smoking cessation outcomes. ${ }^{20}{ }^{21}$ Because the most recent thinking about $\mathrm{MI}^{8}$ has led to the identification of overlapping processes 
that include engaging, evoking participants' motivation for change and planning, it may be beneficial for counsellors to specifically avoid or minimise evoking in the latter phases of the progression towards change. Thus, these data suggest it might be useful to consider ways to keep the positive benefits in an MI approach while curbing the negative effects on cognitive complexity for clients in more exploratory phases of treatment. The present studies, while not following participants through multiple phases, does suggest that in MI contexts, sometimes simplicity is associated with success more than complexity.

\section{Caveats and limitations}

This study is not without its limitations. First, we do not make strong claims about the causal influence from complexity to outcome. Rather, we argue that these data are largely consistent with the part of the phase model tested in the present work, but future studies would be necessary to more firmly establish a clear causal connection via experimental manipulations. However, given that no evidence currently directly ties cognitive complexity to success in outcomes during real-time sessions, the strong and unique association found in the present study is nonetheless an important advance.

It is further worth noting that we only test one part of the phase model in the present work-the part of figure 1 that suggests occasional/exploratory smokers would show more improvement if they had lower complexity. We do not test the other parts of the model. However, this test is important even if the phase model itself-taken in totalturns out to be wrong. Disconnected from the phase model, these results at a minimum demonstrate that clients who succeeded in an MI smoking intervention had lower complexity during sessions than those who did not succeed. While one cannot draw firm causal conclusions, it is nonetheless worth considering why this phenomena is occurring. Because integrative complexity consistently was uniquely associated with client success in our results even when controlling for other common factors, we feel the most likely explanation is that integrative complexity is worthy of attention as playing a potentially important role in change.

In offering this interpretation, we follow a similar path as other researchers who have performed secondary analyses on the linguistic properties of MI counselling sessions. ${ }^{52}$ As in that prior work, our outcome variable occurs (during the course of the study) at a later point in time than the sessions themselves, and thus, it is more likely that a causal arrow between the two variables would go from complexity to outcome than vice versa. Indeed, in demonstrating differences across client success based on linguistic coding of sessions' commitment language, one well-cited paper ${ }^{52}$ argued that '... attention to client commitment language as a reliable in-session indicator of the probability of target behavior change appears to be warranted' (p. 875). Later, they elaborated : 'Accordingly, attempts to strengthen a client's desire, self-efficacy (ability), need, and reasons to change should lead to gains in overall commitment strength and ultimately to behavior change' (p. 876). In brief, throughout, they treated their results on commitment language-using a similar design and method as we use here-to indicate the real possibility that their linguistic variable was important enough to warrant consideration in making changes that will help people foster long-term behavioural success. We follow the same logic here. Thus, while we cannot draw strong causal conclusions, we (like prior researchers) think it is valuable to study what differentiates a successful set of sessions from an unsuccessful set. To the degree that complexity uniquely differentiates those sessionsand our evidence demonstrates that it does-it suggests that a larger randomised study that can more fully determine causality is in order. Our study is an important first step in that chain.

A further limitation of the present work is that interpretation of these data should be limited to occasional smokers and possibly college populations. While this population is very important in its own right and is an important bridge between youth and adult smoking behaviours, ${ }^{11}$ it nonetheless does not necessarily represent non-college populations. Especially given the fact that the phase model predicts a potentially divergent complexity-success pattern for persons in different phases (see figure 1), it is an important task for future research to consider different populations of smokers. The present results should be viewed as relevant to a specific sample that clearly had a particular set of properties (modest motivation to quit and high confidence in their ability to quit). While that sample is meaningful in its own right, additional research is necessary to further clarify the boundaries of the effects reported here.

In addition, we measured the cognitive complexity of participants during real counselling sessions and did not have long-term follow-ups concerning their level of complexity outside of those contexts. This raises the possibility that the measured level of complexity may not reflect the real thoughts of participants. Although it is possible that these studies reflect a change in superficial verbiage rather than in participants' actual thinking, research on open-ended complexity measures typically suggests that it is a marker of private cognitions rather than simply superficial self-presentation. ${ }^{4379} 80$ Moreover, in general, researchers have argued that transcriptions of interviews, such as we use in the present work, likely minimise self-presentational concerns in various forms of linguistic analyses, ${ }^{81-84}$ and it is common in MI linguistic research to use transcripts of counselling sessions as primary source material. ${ }^{652}$

Finally, the present work should be seen as complementary to work examining biological factors relevant to smoking cessation ${ }^{85}$ and is not intended to supplant or invalidate those perspectives. Indeed, in a biopsychosocial model, health outcomes are multiply determined by the interplay of biological, psychological and social factors. ${ }^{86}$ The present study falls squarely within the 'psychological' facet of these and other related models. While the 
present study does not integrate this psychological facet with biological or social factors explicitly, it follows in the footsteps of a long line of research attempting to illuminate the psychological mechanisms ${ }^{65287}$ that underpin change in MI contexts.

\section{Author affiliations}

${ }^{1}$ Department of Psychology, University of Montana, Missoula, Montana, USA

${ }^{2}$ School of Public and Community Health Sciences, University of Montana, Missoula, Montana, USA

${ }^{3}$ Center for Children's Healthy Lifestyles \& Nutrition, Children's Mercy Kansas City \& Department of Pediatrics, University of Kansas School of Medicine, Kansas City, Missouri, USA

${ }^{4}$ Department of Psychology, Roanoke College, Salem, Virginia, USA

${ }^{5}$ Department of Psychology, Syracuse University, Syracuse, New York, USA

Acknowledgements The authors would like to thank James Pennebaker for his invaluable help on this project, as well as Alex Luce, Hayley McCullough, James McFarland and Regan Smith for their excellent coding of materials.

Contributors LGC, KJH, DC, LJG and KRC were involved in the study concept and design. All authors were involved in acquisition, analysis, interpretation of data and approval for submission, initial drafting of the manuscript and critical revision of the manuscript. LGC was involved in statistical analysis.

Funding This work was supported by a grant from the National Institutes of Health/National Cancer Institute (grant number 1R15 CA186247-01A1). It was also supported and by a second grant from NIH/NCI (grant number R01 CA107191-05).

Competing interests None declared.

Patient consent Obtained.

Provenance and peer review Not commissioned; externally peer reviewed.

Data sharing statement Scoring appendices and dataset will be made available at http://hs.umt.edu/politicalcognition.

Open Access This is an Open Access article distributed in accordance with the Creative Commons Attribution Non Commercial (CC BY-NC 4.0) license, which permits others to distribute, remix, adapt, build upon this work non-commercially, and license their derivative works on different terms, provided the original work is properly cited and the use is non-commercial. See: http://creativecommons.org/ licenses/by-nc/4.0/

(C) Article author(s) (or their employer(s) unless otherwise stated in the text of the article) 2017. All rights reserved. No commercial use is permitted unless otherwise expressly granted.

\section{REFERENCES}

1. Jha P, Ramasundarahettige C, Landsman V, et al. 21st-century hazards of smoking and benefits of cessation in the United States. N Engl J Med 2013;368:341-50.

2. Schroeder SA. New evidence that cigarette smoking remains the most important health hazard. N Engl J Med 2013;368:389-90.

3. Thun MJ, Carter BD, Feskanich D, et al. 50-year trends in smoking-related mortality in the United States. $N$ Engl J Med 2013;368:351-64.

4. Fiore M. Treating tobacco use and dependence. Rockville, Md: U.S. Dept. of Health and Human Services, Public Health Service, 2008.

5. Lundahl B, Moleni T, Burke BL, et al. Motivational interviewing in medical care settings: a systematic review and meta-analysis of randomized controlled trials. Patient Educ Couns 2013:93:157-68.

6. Lindqvist $\mathrm{H}$, Forsberg LG, Forsberg L, et al. Motivational interviewing in an ordinary clinical setting: a controlled clinical trial at the Swedish National Tobacco Quitline. Addict Behav 2013;38:2321-4.

7. Lindqvist $H$, Forsberg L, Enebrink $\mathrm{P}$, et al. The relationship between counselors' technical skills, clients' in-session verbal responses, and outcome in smoking cessation treatment. J Subst Abuse Treat 2017;77:141-9.

8. Miller W, Rollnick S. Motivational interviewing: Helping people change. 3rd ed. New York: The Guilford Press, 2013.

9. Butler C, Rollnick S, Cohen D, et al. Motivational consulting versus brief advice for smokers in general practice: a randomized trial. $\mathrm{Br}$ J Gen Pract 1999;49:611-6.
10. Borrelli B, Novak S, Hecht J, et al. Home health care nurses as a new channel for smoking cessation treatment: outcomes from project CARES (Community-nurse Assisted Research and Education on Smoking). Prev Med 2005;41:815-21.

11. Harris KJ, Catley D, Good GE, et al. Motivational interviewing for smoking cessation in college students: a group randomized controlled trial. Prev Med 2010;51:387-93.

12. Wakefield $\mathrm{M}$, Olver I, Whitford $\mathrm{H}$, et al. Motivational interviewing as a smoking cessation intervention for patients with cancer. Nurs Res 2004:53:396-405.

13. Colby SM, Monti PM, O'Leary Tevyaw T, et al. Brief motivational intervention for adolescent smokers in medical settings. Addict Behav 2005;30:865-74.

14. Curry SJ. Youth tobacco cessation: filling the gap between what we do and what we know. Am J Health Behav 2003;27:99-102.

15. Pbert L, Osganian SK, Gorak D, et al. A school nurse-delivered adolescent smoking cessation intervention: a randomized controlled trial. Prev Med 2006;43:312-20.

16. Prokhorov AV, Yost T, Mullin-Jones M, et al. ' Look at your health': outcomes associated with a computer-assisted smoking cessation counseling intervention for community college students. Addict Behav 2008;33:757-71.

17. Soria R, Legido A, Escolano C, et al. A randomised controlled trial of motivational interviewing for smoking cessation. Br J Gen Pract 2006;56:768-74.

18. Valanis B, Lichtenstein E, Mullooly JP, et al. Maternal smoking cessation and relapse prevention during health care visits. Am J Prev Med 2001;20:1-8.

19. Wakefield $\mathrm{M}$, Olver $\mathrm{I}$, Whitford $\mathrm{H}$, et al. Motivational interviewing as a smoking cessation intervention for patients with cancer: randomized controlled trial. Nurs Res 2004;53:396-405.

20. Heckman CJ, Egleston BL, Hofmann MT. Efficacy of motivational interviewing for smoking cessation: a systematic review and metaanalysis. Tob Control 2010;19:410-6.

21. Hettema JE, Hendricks PS. Motivational interviewing for smoking cessation: a meta-analytic review. J Consult Clin Psychol 2010;78:868-84.

22. Markland D, Ryan RM, Tobin VJ, et al. Motivational interviewing and self-determination theory. J Soc Clin Psychol 2005;24:811-31.

23. Miller W, Rollnick S. Motivational interviewing. New York: Guilford Press, 2002.

24. Christopher PJ, Dougher MJ. A behavior-analytic account of motivational interviewing. Behav Anal 2009;32:149-61.

25. Miller WR, Rose GS. Toward a theory of motivational interviewing Am Psychol 2009;64:527-37.

26. Cupertino AP, Berg C, Gajewski B, et al. Change in self-efficacy, autonomous and controlled motivation predicting smoking. $J$ Health Psychol 2012;17:640-52.

27. Conway LG, Conway KR, Gornick LJ, et al. Automated integrative complexity. Polit Psychol 2014;35:603-24.

28. Conway LG, Thoemmes F, Allison AM, et al. Two ways to be complex and why they matter: implications for attitude strength and lying. $J$ Pers Soc Psychol 2008;95:1029-44.

29. Houck SC, Conway LG, Gornick LJ. Automated integrative complexity: current challenges and future directions. Polit Psychol 2014;35:647-59.

30. Davidson $\mathrm{K}$, Livingstone $\mathrm{S}$, McArthur $\mathrm{K}$, et al. An integrative complexity analysis of cognitive behaviour therapy sessions for borderline personality disorder. Psychol Psychother 2007;80:513-23.

31. Conway LG, Dodds DP, Towgood KH, et al. The biological roots of complex thinking: are heritable attitudes more complex? J Pers 2011;79:101-34.

32. Suedfeld P, Piedrahita LE. Intimations of mortality: integrative simplification as a precursor of death. J Pers Soc Psychol 1984;47:848-52

33. Suedfeld P, Fell C, Krell R. Structural aspects of survivors' thinking about the Holocaust. J Trauma Stress 1998;11:323-36.

34. Pancer SM, Pratt M, Hunsberger B, et al. Thinking ahead: complexity of expectations and the transition to parenthood. $J$ Pers 2000;68:253-79.

35. Conway LG, Conway KR. The terrorist rhetorical style and its consequences for understanding terrorist violence. Dynamics of Asymmetric Conflict 2011;4:175-92.

36. Conway LG, Gornick LJ, Burfeind C, et al. Does complex or simple rhetoric win elections? An integrative complexity analysis of U.S. presidential campaigns. Polit Psychol 2012;33:599-618.

37. Conway L, Gornick L. Cognitive complexity. Christie DEncyclopedia of peace psychology. 1st ed. Hoboken, New Jersey: Wiley_Blackwell, 2011.

38. Bieri J, Atkins A, Briar S, et al. Clinical and social judgment: The discrimination of behavioral information. New York: Wiley, 1966. 
39. Fletcher GJO, Danilovics P, Fernandez G, et al. Attributional complexity: An individual differences measure. J Pers Soc Psychol 1986;51:875-84.

40. Neuberg SL, Newsom JT. Personal need for structure: Individual differences in the desire for simpler structure. J Pers Soc Psychol 1993;65:113-31.

41. Suedfeld P, Tetlock PE, Ramirez C, War RC. War, Peace, and Integrative Complexity. J Conflict Resolut 1977;21:427-42.

42. Suedfeld P, Fell C, Krell R. Structural aspects of survivors' thinking about the Holocaust. J Trauma Stress 1998;11:323-36.

43. Tetlock PE, Tyler A. Churchill's cognitive and rhetorical style: the debates over nazi intentions and self-government for india. Polit Psychol 1996;17:149.

44. Thoemmes FJ, Conway LG. Integrative complexity of 41 U.S. presidents. Polit Psychol 2007;28:193-226.

45. Conway LG, Gornick LJ, Houck SC, et al. Are conservatives really more simple-minded than liberals? The domain specificity of complex thinking. Polit Psychol 2016;37:777-98.

46. Hunsberger B, Lea J, Pancer SM, et al. Making Life Complicated: Prompting the Use of Integratively Complex Thinking. J Pers 1992:60:95-114.

47. Suedfeld P. Verbal indices of conceptual complexity: manipulation by instructions. Psychon Sci 1968;12:377.

48. Davidson MM, Cronk NJ, Harris KJ, et al. Strategies to recruit and retain college smokers in cessation trials. Res Nurs Health 2010;33:155

49. Mata J, Todd PM, Lippke S. When weight management lasts. Lower perceived rule complexity increases adherence. Appetite 2010;54:37-43.

50. Murdaugh C, Insel K. In: Shumaker S, Ockene J, Riekert K, eds. The Handbook of Health Behavior Change. 3rd ed. New York: Springer Publishing Co, 2009.

51. Suedfeld P, Leighton D, Conway L. Integrative Complexity and Cognitive Management in International Confrontations: Research and Potential Applications. Fitzduff MStout C, ed. The psychology of resolving global conflicts: From war to peace: Nature vs Nuture. 1st ed. Westport, CT: Praeger Security International, 2006:211-37.

52. Amrhein PC, Miller WR, Yahne CE, et al. Client commitment language during motivational interviewing predicts drug use outcomes. $J$ Consult Clin Psychol 2003;71:862-78.

53. Menninga KM, Dijkstra A, Gebhardt WA. Mixed feelings: ambivalence as a predictor of relapse in ex-smokers. Br J Health Psychol 2011;16:580-91.

54. Xiaoquan Zhao, Xiaomei Cai. The Role of Ambivalence in College Nonsmokers' Information Seeking and Information Processing. Communic Res 2008;35:298-318.

55. Lipkus IM, Pollak KI, McBride CM, et al. Assessing attitudinal ambivalence towards smoking and its association with desire to quit among teen smokers. Psychol Health 2005;20:373-87.

56. Baker TB, Mermelstein R, Collins LM, et al. New methods for tobacco dependence treatment research. Ann Behav Med 2011;41:192-207.

57. McEwen A, West R. The PRIME approach to giving up smoking. Practice Nursing 2010;21:145-53.

58. Tetlock PE, Bernzweig J, Gallant JL. Supreme Court decision making: Cognitive style as a predictor of ideological consistency of voting. J Pers Soc Psychol 1985;48:1227-39.

59. Tetlock PE, Armor D, Peterson RS. The slavery debate in antebellum America: cognitive style, value conflict, and the limits of compromise. $J$ Pers Soc Psychol 1994;66:115-26.

60. Linville PW. The complexity-extremity effect and age-based stereotyping. J Pers Soc Psychol 1982;42:193-211.

61. Suedfeld P, Leighton DC. Early communications in the war against terrorism: an integrative complexity analysis. Polit Psychol 2002;23:585-99.

62. Suedfeld P, Bluck S, Ballard EJ. The effects of emotional involvement and psychological distance on integrative complexity1. J App/ Soc Psychol 1994;24:443-52.

63. Tetlock PE, Skitka L, Boettger R. Social and cognitive strategies for coping with accountability: conformity, complexity, and bolstering. J Pers Soc Psychol 1989;57:632-40.
64. Harris KJ, Golbeck AL, Cronk NJ, et al. Timeline follow-back versus global self-reports of tobacco smoking: a comparison of findings with nondaily smokers. Psychol Addict Behav 2009;23:368-72.

65. Hays. W. Statistics, Fourth Edition. 8. Holt New York: Rinehart and Winston:198.

66. Baker-Brown G, Ballard E, Bluck S, et al. The conceptual/integrative complexity scoring manual. Smith C, ed. Motivation and personality: Handbook of thematic content analysis. 1st ed. Cambridge: Cambridge University Press, 1992:605-11.

67. Suedfeld P, Tetlock PE, Ramirez C. War, Peace, and Integrative Complexity. J Conflict Resolut 1977;21:427-42.

68. Ryan RM, Connell JP. Perceived locus of causality and internalization: examining reasons for acting in two domains. $J$ Pers Soc Psychol 1989;57:749-61.

69. Dijkstra A, de Vries H, Bakker M. Pros and cons of quitting, selfefficacy, and the stages of change in smoking cessation. $J$ Consult Clin Psychol 1996;64:758-63.

70. Dijkstra A, Tromp D, Conijn B. Stage-specific psychological determinants of stage transition. Br J Health Psychol 2003;8:423-37.

71. Dijkstra A, Buunk AP. Self-evaluative emotions and expectations about self-evaluative emotions in health-behaviour change. Br J Soc Psychol 2008;47:119-37.

72. Heatherton TF, Kozlowski LT, Frecker RC, et al. The fagerström test for nicotine dependence: a revision of the fagerström tolerance questionnaire. Br J Addict 1991;86:1119-27.

73. Biener L, Abrams DB. The Contemplation Ladder: validation of a measure of readiness to consider smoking cessation. Health Psychol 1991;10:360-5

74. Harris KJ, Ahluwalia JS, Catley D, et al. Successful recruitment of minorities into clinical trials: the kick It at Swope project. Nicotine Tob Res 2003;5:575-84.

75. Centers for Disease Control and Prevention. Current cigarette smoking among adults aged $\geq 18$ Years-United States, 2005-2010 [Internet]. Vital Signs 2011:1207-12 http://www.cdc.gov/mmwr

76. Davidson K, Livingstone S, McArthur K, et al. An integrative complexity analysis of cognitive behaviour therapy sessions for borderline personality disorder. Psychol Psychother 2007;80:513-23.

77. de Vries B, Lehman A. The complexity of personal narratives. de Vries BLehman A, ed. Aging and biography: Explorations in adult development. 1st ed. New York, NY: Springer Publishing Co, 1996:149-66.

78. Ahluwalia JS, Okuyemi K, Nollen N, et al. The effects of nicotine gum and counseling among African American light smokers: a $2 \times 2$ factorial design. Addiction 2006;101:883-91.

79. Conway L, Suedfeld P, Tetlock P. Integrative complexity and political decisions that lead to war or peace. Christie D, ed. Peace, conflict, and violence: Peace psychology for the 21st century. 1st ed. Upper Saddle River, NJ, US: Prentice Hall/Pearson Education, 2001:66-75.

80. Suedfeld P, Bluck S. Changes in integrative complexity prior to surprise attacks. J Conflict Resolut 1988;32:626-35.

81. Dille B, Young MD. The Conceptual Complexity of Presidents Carter and Clinton: an Automated Content Analysis of Temporal Stability and Source Bias. Polit Psychol 2000;21:587-96.

82. Hermann MG. Explaining Foreign Policy Behavior Using the Persona Characteristics of Political Leaders. International Studies Quarterly 1980;24:7.

83. Hermann M. Handbook for assessing personal characteristics and foreign policy orientations of political leaders 1 st ed. Columbus, $\mathrm{OH}$ : Mershon Center, 1983.

84. Hermann M. Personality and foreign policy decision making: A study of 53 heads of government. In: Sylvan D, Chan S, Foreign policy decision making: Perception, cognition, and artificial intelligence. 1st ed. New Yor: Praeger, 1984:53-80.

85. Taylor GMJ, Taylor AE, Thomas KH, et al. The effectiveness of varenicline versus nicotine replacement therapy on long-term smoking cessation in primary care: a prospective cohort study of electronic medical records. Int J Epidemiol 2017:1-10.

86. Gatchel RJ, Oordt MS. Clinical health psychology and primary care: Practical advice and clinical guidance for successful collaboration. Washington, D C: American Psychological Association, 2003.

87. Catley D, Harris KJ, Mayo MS, et al. Adherence to Principles of Motivational Interviewing and Client Within-Session Behavior. Behav Cogn Psychother 2006;34:43-56. 